\title{
LETTER
}

\section{Sepsis as a major determinant of outcome in critically ill HIV/AIDS patients: don't forget acute kidney injury}

\author{
José António Lopes* and Sofia Jorge \\ See related research by Japiassú et al., http://ccforum.com/content/14/4/R152
}

In a previous issue of Critical Care, we read with interest the article by Japiassú and colleagues [1] in which severe sepsis was analyzed as a major determinant of outcome of critically ill patients with HIV/AIDS. For this purpose, the authors prospectively studied 88 HIV-infected patients admitted to the intensive care unit and analyzed the impact of severe sepsis on 28-day and 6-month mortality. The occurrence of severe sepsis was associated with a threefold increased risk of death at these follow-up times. Furthermore, cardiovascular and respiratory dysfunctions were associated with increased mortality. Those are important findings and improve medical knowledge on the key factors determining survival in a specific population that has markedly increased in recent years [2]. Surprisingly, however, the authors have not evaluated the impact of renal dysfunction on patient outcome. Here, we would like to underline the prognostic importance of acute kidney injury (AKI) on the outcome of critically ill patients with HIV. AKI is a common complication in this setting and is independently associated with increased mortality. In addition, sepsis is a leading cause of AKI among those patients [3]. These findings have also been demonstrated in non-critically ill, hospitalized patients with HIV [4]. Therefore, the burden of mortality associated with sepsis could be explained, in part, by the high incidence of associated AKI. Prompt recognition and aggressive treatment of sepsis could be crucial in diminishing both the occurrence of AKI and mortality in critically ill patients with HIV.

\section{Authors' response}

Rodrigo Teixeira Amâncio, André Miguel Japiassú and Fernando Augusto Bozza

Acute renal failure (ARF) is one of the major determinants of hospital outcome in the critically ill population, and severe sepsis is the main cause of ARF in this setting [5]. Patients with HIV/AIDS show a predisposition to renal dysfunction, as the HIV and antiretroviral drugs can lead to renal tubular dysfunction [6]. Lopes and colleagues [3,4] have reported that ARF is independently associated with hospital mortality of critically ill patients with HIV.

We evaluated $88 \mathrm{HIV}$-positive critically ill patients, seeking the main risk factors for mortality [1]. Severe sepsis was the major factor associated with 28-day and 6-month mortality. CD4 cell count, viral load, and the use of antiretrovirals were not associated with survival. As

*Correspondence: jalopes93@hotmail.com

Department of Nephrology and Renal Transplantation, Hospital de Santa Maria, Centro Hospitalar de Lisboa Norte, EPE, Av. Prof. Egas Moniz, 1649-035 Lisboa, Portugal suggested by Lopes and Jorge, we reanalyzed the data about organ dysfunctions in that cohort, targeting hospital outcome. Nonsurvivors presented higher rates of renal (63\% versus $33 \%, P=0.01$ ) and hematological (42\% versus $16 \%, P=0.009$ ) dysfunctions than survivors of HIV/AIDS. We included these organ dysfunctions in a new multivariate analysis; severe sepsis remained the main factor associated with hospital survival (odds ratio (OR) 4.2, 95\% confidence interval (CI) 1.2 to 14.2 , $P=0.02$ ), and renal (OR 2.6, 95\% CI 0.9 to $7.4, P=0.06$ ) and hematological (OR 2.7, 95\% CI 0.9 to $8.5, P=0.08$ ) dysfunction had borderline results (Table 1). We also reevaluated our current cohort, reaching 139 patients with $\mathrm{HIV}$, and the presence of renal failure was related to poorer prognosis but was not associated with hospital mortality in the multivariate analysis (OR 1.9, 95\% CI 0.8 to $4.4, P=0.15)$. We agree that renal dysfunction, especially when associated with severe sepsis, can reduce survival among critically ill patients with HIV/AIDS. 
Table 1. Acute organ dysfunctions on the first day of intensive care unit stay

\begin{tabular}{|c|c|c|c|c|c|}
\hline \multirow[b]{2}{*}{ Organ dysfunctions } & \multicolumn{3}{|c|}{ Univariate analysis } & \multicolumn{2}{|c|}{ Multivariate analysis } \\
\hline & Survivors & Nonsurvivors & $P$ value & Odds ratio $(95 \% \mathrm{Cl})$ & $P$ value \\
\hline Cardiovascular & $62 \%$ & $74 \%$ & 0.25 & $0.84(0.25-2.86)$ & 0.78 \\
\hline Respiratory & $60 \%$ & $72 \%$ & 0.26 & $0.89(0.24-3.31)$ & 0.86 \\
\hline Renal & $33 \%$ & $63 \%$ & 0.01 & $2.65(0.95-7.36)$ & 0.06 \\
\hline Hematological & $16 \%$ & $42 \%$ & 0.009 & $2.75(0.89-8.54)$ & 0.08 \\
\hline Neurological & $33 \%$ & $37 \%$ & 0.82 & - & - \\
\hline Hepatic & $13 \%$ & $28 \%$ & 0.11 & $0.90(0.75-10.4)$ & 0.40 \\
\hline
\end{tabular}

Data extracted from Japiassú et al. [1]. Cl, confidence interval.

\section{Abbreviations}

$\mathrm{AKI}$, acute kidney injury; ARF, acute renal failure; $\mathrm{Cl}$, confidence interval; $\mathrm{OR}$, odds ratio.

\section{Competing interests}

The authors declare that they have no competing interests.

\section{Authors' contributions}

JAL and SJ drafted the letter, revised it critically for important intellectual content, and read and approved the final manuscript.

\section{Published: 10 December 2012}

\section{References}

1. Japiassú AM, Amâncio RT, Mesquita EC, Medeiros DM, Bernal HB, Nunes EP, Luz PM, Grinsztejn B, Bozza FA: Sepsis as a major determinant of outcome in critically ill HIV/AIDS patients. Crit Care 2010, 14:R152.

2. Narasimhan M, Posner AJ, DePalo VA, Mayo PH, Rosen MJ: Intensive care in patients with HIV infection in the era of highly active antiretroviral therapy. Chest 2004, 125:1800-1804
3. Lopes JA, Fernandes J, Jorge S, Neves J, Antunes F, Martins Prata M: Acute renal failure in critically ill HIV-infected patients. Crit Care 2007, 11:404

4. Lopes JA, Melo MJ, Viegas A, Raimundo M, Câmara I, Antunes F, Gomes da Costa A: Acute kidney injury in hospitalized HIV-infected patients: a cohort analysis. Nephrol Dial Transplant 2011, 26:3888-3894.

5. Uchino S, Kellum JA, Bellomo R, Doig GS, Morimatsu H, Morgera S, Schetz M, Tan I, Bouman C, Macedo E, Gibney N, Tolwani A, Ronco C; Beginning and Ending Supportive Therapy for the Kidney (BEST Kidney) Investigators: Acute renal failure in critically ill patients: a multinational, multicenter study. JAMA 2005, 294:813-818.

6. Dauchy FA, Lawson-Ayayi S, de La Faille R, Bonnet F, Rigothier C, Mehsen N, Miremont-Salamé G, Cazanave C, Greib C, Dabis F, Dupon M: Increased risk of abnormal proximal renal tubular function with HIV infection and antiretroviral therapy. Kidney Int 2011, 80:302-309.

doi:10.1186/cc11870

Cite this article as: Lopes JA, Jorge S: Sepsis as a major determinant of outcome in critically ill HIV/AIDS patients: don't forget acute kidney injury. Critical Care 2012, 16:468 